Rabaska

Revue d'ethnologie de l'Amérique française

\title{
Exilda Doucet-Hébert (1919-2008)
}

\section{Robert Richard}

Volume 7, 2009

URI : https://id.erudit.org/iderudit/038346ar

DOI : https://doi.org/10.7202/038346ar

Aller au sommaire du numéro

Éditeur(s)

Société québécoise d'ethnologie

ISSN

1703-7433 (imprimé)

1916-7350 (numérique)

Découvrir la revue

Citer ce document

Richard, R. (2009). Exilda Doucet-Hébert (1919-2008). Rabaska, 7, 138-140.

https://doi.org/10.7202/038346ar d'utilisation que vous pouvez consulter en ligne.

https://apropos.erudit.org/fr/usagers/politique-dutilisation/ 


\section{Nécrologie}

\section{Exilda Doucet-Hébert (1919-2008)}

Cinquième d'une famille de seize enfants, la conteuse acadienne Exilda Doucet-Hébert est née le 26 juillet 1919 à Fontaine dans le sud-est du Nouveau-Brunswick. Longeant le détroit de Northumberland, le long du littoral acadien, cette petite communauté était située au nord-ouest du comté de Kent à environ une quarantaine de kilomètres au nord du Pays de la Sagouine (Bouctouche). Aujourd'hui, Fontaine fait partie du Parc national du Canada Kouchibouguac. Jusqu'en 1963, Exilda a donc vécu dans une : « [...] mosaïque de tourbières, de marais salés, d'estuaires, de systèmes d'eau douce, de lagunes abritées, d'anciens champs et de forêts aux arbres majestueux... (Parc Canada) ». Avant même de terminer sa première année scolaire, Exilda a été obligée d'abandonner l'école afin $\mathrm{d}$ 'aider sa mère à la maison. Comme bien

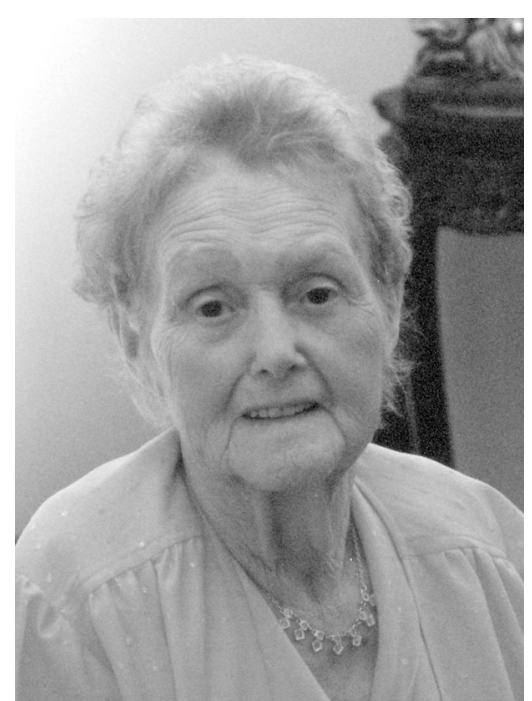

Exilda Doucet-Hébert

Source : collection privée, 2002 d'autres familles du voisinage, celle d'Exilda dépendait de la pêche, du travail dans les chantiers en hiver et du travail occasionnel chez les Anglais, de la chasse et de la ferme pour subvenir aux besoins de subsistance. Quant aux besoins de divertissements, la communauté de Fontaine avait entre autres ses conteurs et c'est là qu'Exilda a eu son apprentissage.

«Les crowds se ramassaient, puis ils nous contiont des contes... C'était plaisant. On s'assisait dans un ring, tout le tour de z-eux-là (les conteurs), puis on écoutait... Tu n'entendais pas un mot... La soirée commençait vers $8 \mathrm{~h}$, puis ça finissait jusqu'à 12 heures et parfois 1 heure en nuit. C'était de même à tous les soirs... On était assez pauvre. On ne pouvait pas payer rien... Ça faisait passer le temps... dans ce temps-là. C'est rien que ça qu'une 
personne passait le temps avec... Il n'y avait pas de radio, pas de TV... ». Les conteurs décrits par Exilda étaient ses oncles maternels, Pierre et Ben, son oncle paternel Médée ainsi que ses parents Isabelle Hébert et Mélème Doucet. Même si ces derniers étaient analphabètes, le répertoire de contes d'Exilda a été puisé à même ces conteurs. De son mariage, à 18 ans, avec Edmond Hébert, dix enfants sont nés entre 1940 et 1963 . Quelque temps après la naissance du fils cadet d'Exilda, le ménage s'est installé à Richibouctou (mon village natal). Et cette même année, la télévision a fait son entrée dans le nouveau logis d'Exilda. Du point de vue de la collecte folklorique, il faudra attendre près d'une trentaine d'années afin que le répertoire de contes d'Exilda se retrouve sur ruban magnétique. Dieu merci, Exilda m'a offert le privilège d'être le premier collecteur à l'enregistrer.

Ma première rencontre avec Exilda n'était pas du simple hasard, car je l'avais croisée maintes fois au domicile de mes parents. Ma mère entretenait une relation d'amitié avec celle-ci depuis le début des années 1980. D'emblée, mes débuts dans la collecte du folklore se sont faits à l'été 1990. Dans le domaine du conte traditionnel, j'ai obtenu mon premier enregistrement avec une de mes informatrices, soit Séraphie Daigle-Martin de Richibouctou (répertoire de 152 contes et 223 versions) en janvier 1992. C'était ma première expérience avec une conteuse de la tradition. Quelques mois plus tard, le 14 mars, vint ma première entrevue avec Exilda où j'ai enregistré sept magnifiques contes. J'étais au septième ciel. Lors de cette entrevue, elle s'est même permis de dire : "J'en ai assez entendu que je peux en faire moimême. Je peux en forger... Quand tu sais assez de contes, tu peux en faire... ». Évidemment, j'étais loin de connaître l'ampleur de son répertoire. Par la suite, une collaboration avec les chercheurs Jean-Pierre Pichette et Ronald Labelle s'est forgée dans la même année afin d'inscrire la mémoire d'Exilda Doucet-Hébert dans les archives. Conséquemment, ce sont 93 contes (plus de 50 contes sont considérés comme exceptionnels) et 224 versions qui sont colligés, de 1992 à 1998, et déposés par ces derniers aux archives du Centre d'études acadiennes Anselme-Chiasson (CÉAAC). D'ailleurs, selon l'article de Jean-Pierre Pichette intitulé « L'Inventaire d'une mémoire Richibouctoise - Exilda Hébert, conteuse » (Les Cahiers de la Société historique acadienne, vol. 34, $\mathrm{n}^{\circ}$ 1, mars 2003, p. 4-21), Exilda est au troisième rang dans un classement des meilleurs informateurs dans le domaine du conte populaire au Canada français. D'après l'auteur de cet article, ce sont 84 contes du répertoire d'Exilda qui ont été classés selon la typologie d'Aarne-Thompson dont les deux tiers sont des contes merveilleux, seize, des contes facétieux et douze, des contes religieux, réalistes et de l'ogre stupide dont la durée moyenne est d'un peu plus de treize minutes, le tout variant de trois à trentecinq minutes. 
Exilda Doucet-Hébert est décédée le 9 septembre 2008 à la Villa Maria de Saint-Louis-de-Kent des suites d'une longue maladie. Les funérailles ont eu lieu le 12 septembre en l'église de Saint-Louis-de-Gonzague de Richibouctou. À la demande de Maria Hébert-Daigle, la fille d'Exilda, j'ai eu l'honneur de présenter au salon funéraire l'importance du répertoire d'Exilda ainsi que de répondre aux questions de la famille sur le sujet. Une des petites-filles d'Exilda m'a même demandé de raconter un conte et c'est ce que j'ai fait. Pour la famille d'Exilda, il y a unanimité dans les commentaires dont voici un clin d'œil de sa fille Maria : «Quand maman contait des contes, mes cousins et cousines venaient chez nous... "Exilda, contes-tu des contes ce soir ?..." C'était tout le temps dans le calme. C'était accueillant. C'était plaisant. On dirait que ça relaxait à la fin de la journée... Ça reposait...C'était un temps qu'on avait les contes... qu'on n'avait pas de problème... On n'avait pas de problème à ce temps-là... Si on avait faim, on n'avait plus faim... Si on avait soif, on n'avait plus soif... On était juste dans le temps... On dirait juste dans le conte... ». Récemment, six conteurs de la Nuit internationale du conte en Acadie (www.nicacadie.com) ont rendu hommage à Exilda Doucet-Hébert devant un auditoire d'une trentaine de personnes, avec plusieurs membres de la famille d'Exilda, qui s'étaient réunis à la polyvalente Monseigneur-Marcel-François-Richard de Saint-Louis-de-Kent. Ceux-ci ont repris une partie du répertoire d'Exilda. Robert Richard a conté le « Bâtiment sur terre et sur mer» (conte-type 513B), Kevin Arseneau, celui du « Cheval qui chiait de l'argent» (conte-type 1535), Yvette Pitre, celui de «Paul et Plume» (conte-type 301A), Nelson Michaud, celui d' " Anne de la source marine » (conte-type 425), Anita Savoie, celui des « Deux enfants abandonnés dans le bois » (conte-type 327I - 510B) et Ronald Labelle, celui de « Bonnet rouge $»$ (conte-type 313$)$.

ROBERT RiCHARD

Université de Moncton, Moncton

\section{Source}

Enregistrements audio de la collection Robert Richard déposés aux archives de folklore du Centre d'études acadiennes Anselme-Chiasson de l'Université de Moncton. 